CLINICAL STUDY

\title{
TSH-receptor autoimmunity in Graves' disease after therapy with anti-thyroid drugs, surgery, or radioiodine: a 5-year prospective randomized study
}

\author{
Peter Laurberg, Göran Wallin ${ }^{1}$, Leif Tallstedt ${ }^{2}$, Mirna Abraham-Nordling ${ }^{1}$, Göran Lundell ${ }^{3}$ and Ove Tørring ${ }^{4}$ \\ Department of Endocrinology and Internal Medicine, Aalborg Hospital, Aarhus University Hospital, DK-9000 Aalborg, Denmark, \\ ${ }^{1}$ Department of Molecular Institution of Surgery, Karolinska University Hospital, Stockholm, Sweden, ${ }^{2}$ Department of Ophthalmology, Karolinska \\ Institutet, St Erik's Eye Hospital, Stockholm, Sweden, ${ }^{3}$ Radiumhemmet, Department of General Oncology, Karolinska University Hospital, Stockholm, \\ Sweden and ${ }^{4}$ Department of Endocrinology and Internal Medicine and Institution of Clinical Research and Education, Södersjukhuset, Karolinska Institutet, \\ Stockholm, Sweden \\ (Correspondence should be addressed to P Laurberg; Email: peter.laurberg@rn.dk)
}

\begin{abstract}
Introduction: Autoimmunity against the TSH receptor is a key pathogenic element in Graves' disease. The autoimmune aberration may be modified by therapy of the hyperthyroidism.

Objective: To compare the effects of the common types of therapy for Graves' hyperthyroidism on TSHreceptor autoimmunity.

Methods: Patients with newly diagnosed Graves' hyperthyroidism aged 20-55 years were randomized to medical therapy, thyroid surgery, or radioiodine therapy (radioiodine was only given to patients $\geq 35$ years of age). L-thyroxine ( $\left.\mathrm{L}_{-} \mathrm{T}_{4}\right)$ was added to therapy as appropriate to keep patients euthyroid. Anti-thyroid drugs were withdrawn after 18 months of therapy. TSH-receptor antibodies (TRAb) in serum were measured before and for 5 years after the initiation of therapy.

Results: Medical therapy $(n=48)$ and surgery $(n=47)$ were followed by a gradual decrease in TRAb in serum, with the disappearance of TRAb in $70-80 \%$ of the patients after 18 months. Radioiodine therapy $(n=36)$ led to a 1-year long worsening of autoimmunity against the TSH receptor, and the number of patients entering remission of TSH-receptor autoimmunity with the disappearance of TRAb from serum during the following years was considerably lower than with the other types of therapy. Conclusion: The majority of patients with Graves' disease gradually enter remission of TSH-receptor autoimmunity during medical or after surgical therapy, with no difference between the types of therapy. Remission of TSH-receptor autoimmunity after radioiodine therapy is less common.
\end{abstract}

European Journal of Endocrinology 158 69-75

\section{Introduction}

Graves' disease is a common autoimmune disorder with various clinical manifestations. The cause for the most prevalent abnormality, hyperthyroidism, is thyrotrophin (TSH)-receptor-stimulating autoantibodies and such antibodies are also believed to cause the diffuse, hypervascular goiter observed in many patients. The exact mechanism leading to Graves' orbitopathy is not firmly established but there is a correlation between disease activity and TSH-receptor antibodies (TRAb) in blood $(1,2)$. Patients with the more uncommon manifestations, pretibial myxedema and thyroid acropachy, are normally characterized by severe general disease with high circulating levels of TRAb (3). TRAb in serum can be measured by their binding to the TSH receptor in vitro, or by more cumbersome biological methods. The performance of assays differ considerably $(4,5)$, but apart from such technical limitations, TRAb in serum is an indicator of the overall autoimmune abnormality in Graves' disease (6).

Like other autoimmune diseases, Graves' disease is most likely caused by a combination of genetic and environmental factors that may also determine the longterm prognosis of the disorder. Over time, the disease may fluctuate in activity and occasionally patients may spontaneously become euthyroid (7). In addition to such a variation, it is well established that the therapy of hyperthyroidism may influence disease activity (6). During prolonged follow-up, TRAb tend to disappear from serum after all types of therapy for hyperthyroidism $(8-10)$.

To obtain more detailed information on the effects of hyperthyroidism therapy on the autoimmune abnormality of Graves' disease, we followed TRAb in serum for a 5-year period in a prospective randomized study comparing the three common therapies, antithyroid drugs, subtotal thyroidectomy, and radioiodine therapy. 


\section{Patients and methods}

All patients between 20 and 55 years of age, who were referred to the involved units in Sweden for untreated Graves' hyperthyroidism and with no previous thyroid disease, were evaluated for inclusion in the study as described in detail previously $(11,12)$. All 179 patients who agreed to enter the study were included and stratified into two groups according to age. Patients, 20-34 years old $(n=60)$, were randomly assigned to treatment with antithyroid drugs plus $\mathrm{L}-$ thyroxine $\left(\mathrm{L}-\mathrm{T}_{4}\right.$; medical therapy) or subtotal thyroidectomy followed by $\mathrm{L}-\mathrm{T}_{4}$ (surgery). Patients, 35-55 years old $(n=119)$, received medical therapy, surgery, or radioiodine. Radioiodine was not used by the involved departments for therapy of Graves' disease in patients below 35 years of age. Randomization was performed by assigning each patient a treatment group consecutively using two lists, one for each age group. On the list, each treatment group occurred in a random order but was balanced to equalize the size of the treatment groups. The lists were unavailable to the clinicians throughout the study, and randomization was performed over the phone.

As described previously in the report on clinical outcomes of therapy (12), 71 patients were randomized to receive medical therapy. Mean (s.D.) tri-iodothyronine $\left(\mathrm{T}_{3}\right)$ was $6.3(2.0) \mathrm{nmol} / \mathrm{l}, \mathrm{T}_{4} 239(72) \mathrm{nmol} / \mathrm{l}$, and free $\mathrm{T}_{4} 59$ (26) $\mathrm{pmol} / \mathrm{l}$ in young patients $(n=30)$; mean (s.D.) $\mathrm{T}_{3}$ was $5.4(1.7) \mathrm{nmol} / \mathrm{l}, \mathrm{T}_{4} 224(55) \mathrm{nmol} / \mathrm{l}$, and free $\mathrm{T}_{4}$ $57(17) \mathrm{pmol} / \mathrm{l}$ in old patients $(n=41)$. Medication was given as $10 \mathrm{mg}$ methimazole, four times daily, for 18 months. Three to five weeks after start, $\mathrm{L}-\mathrm{T}_{4}$ was added in doses of 0.1-0.3 mg per day to keep a normal serum $\mathrm{T}_{3}$ and a slightly suppressed serum TSH. $\mathrm{L}_{-} \mathrm{T}_{4}$ was withdrawn simultaneously with methimazole after 18 months. In the case of methimazole intolerance therapy was continued with propylthiouracil. After 48 months of follow-up, the overall risk of reoccurrence of hyperthyroidism in the medically treated young and old adults was calculated to be 42 and 34\% respectively, as published previously (12). None of the patients staying euthyroid were in need of $\mathrm{L}-\mathrm{T}_{4}$ therapy. Thus, more than one half of the medically treated patients had a prolonged period of euthyroidism without any medication after the halt of therapy.

Patients randomized to surgery $(n=67)$ were pretreated with at least $40 \mathrm{mg}$ propranolol three to four times daily, or an equivalent dose of metoprolol. Seven patients received Lugol's solution in addition. The procedure was subtotal thyroidectomy leaving $\sim 1 \mathrm{~g}$ or less of thyroid tissue in each lobe. $\mathrm{L}_{-} \mathrm{T}_{4}$ therapy was started around day 4 after surgery to avoid hypothyroidism. At the time of inclusion, mean (s.D.) serum $\mathrm{T}_{3}$ was $5.6(1.8) \mathrm{nmol} / \mathrm{l}, \mathrm{T}_{4}$ was 221 (46) $\mathrm{nmol} / \mathrm{l}$, and free $\mathrm{T}_{4}$ was $60(24) \mathrm{pmol} / \mathrm{l}$ in young patients $(n=30)$, while in old patients $\mathrm{T}_{3}$ was $5.4(1.9) \mathrm{nmol} / \mathrm{l}, \mathrm{T}_{4} 224$ (55) $\mathrm{nmol} / \mathrm{l}$, and free $\mathrm{T}_{4} 57$ (25) pmol/l. After 48 months of follow-up, the overall risk of reoccurrence of hyperthyroidism in the surgically treated young and old patients was calculated to be 3 and $8 \%$ respectively (12). All the patients remaining euthyroid received $\mathrm{L}^{-\mathrm{T}_{4}}$ substitution therapy.

Forty-one patients were randomized to ${ }^{131}$ iodine therapy. This was given as a single oral dose calculated to deliver 120 Gray units to the thyroid. $\mathrm{L}-\mathrm{T}_{4}$ therapy was initiated as soon as serum TSH was elevated and/or when serum free $\mathrm{T}_{4}, \mathrm{~T}_{4}$, or $\mathrm{T}_{3}$ were low. At the time of inclusion, mean (s.D.) serum $\mathrm{T}_{3}$ was 5.3 (1.7) $\mathrm{nmol} / \mathrm{l}, \mathrm{T}_{4}$ was 221 (57) $\mathrm{nmol} / \mathrm{l}$, and free $\mathrm{T}_{4}$ was 55 (19) pmol/l. Serum thyroid hormone values were not significantly different between the three treatment groups before therapy. Neither was there any difference in sex distribution or the number of smokers between groups (12). After 48 months of follow-up, the risk of reoccurrence of hyperthyroidism was calculated to be $21 \%$ after ${ }^{131}$ iodine therapy (12). All patients treated with radioiodine ended up being on $\mathrm{L}^{-} \mathrm{T}_{4}$ substitution therapy for hypothyroidism (12).

All TSH receptor antibody (TRAb) measurements were performed by a radioreceptor assay kit provided by RSR Ltd, Cardiff, UK. In this method, ${ }^{125}$ I-labeled bovine TSH compete with TRAb in serum samples to bind to purified porcine TSH receptors, followed by polyethylene glycol precipitation (13). After the completion of our study, new generations of TRAb assays have been developed $(14,15)$, and it has been shown that a minor subset of sera from patients with Graves' disease are falsely negative using the assay employed in our study (15). For the present calculations and presentation of results, we included only patients who were TRAb-positive at the time of inclusion in the study and before therapy.

Among the 179 patients originally included in the study $(11,12)$, results of TRAb measurements before therapy were not available in five, and in another 29 patients the initial TRAb results were within the normal reference range for the assay $(<10 \%$ displacement of ${ }^{125}$ I-labeled TSH). Among the remaining 145 patients, one left the area before 12 months and one left the study with no further samples available because of cancer therapy. Both had been assigned to the medical therapy group. One patient randomized to surgery started treatment with medication and was not operated upon, one rejected radioiodine therapy, one patient randomized to medical therapy did not comply with treatment and control, and two developed intolerance to both methimazole and propylthiouracil and underwent surgery. Further, three patients had a reoccurrence of hyperthyroidism after surgery and subsequently received radioiodine (after 3,13 , and 18 months), and four patients did not become stably euthyroid on medication and underwent surgery after $6,10,11$, and 17 months of therapy. They were all excluded from the general analysis. This analysis included 48 patients (F/M, 41/7) receiving medical therapy, $47(40 / 7)$ undergoing surgery, and $36(31 / 5)$ treated with radioiodine. The number of patients in the three groups 
(medical/surgical/radioiodine) still included in the analyses is as follows: after 1 year, 48/47/36; after 2 years, 43/44/35; after 3 years, 26/40/35; after 4 years, 24/38/34; and after 5 years, 24/38/34.

Serum $\mathrm{T}_{3}, \mathrm{~T}_{4}$, and free $\mathrm{T}_{4}$ were measured as described previously (11). The reference ranges were: $\mathrm{T}_{3}$, $1.1-2.5 \mathrm{nmol} / \mathrm{l} ; \mathrm{T}_{4}, 75-150 \mathrm{nmol} / \mathrm{l}$; and free $\mathrm{T}_{4}$, 9-21 pmol/l.

Patients were included after informed consent, and the protocol was approved according to Swedish ethics regulations.

\section{Calculations and statistical analyses}

In this prolonged multicenter study, it was not possible to arrange control and blood sampling on precise dates for the entire 5-year period, and control had to some degree to be adapted to the individual patient's need $(11,12)$. For the evaluation of TRAb variation after therapy we constructed curves for each patient from the available results of measurements, and the TRAb value at the specific time point indicated was read and used for calculations. The number of TRAb results from each patient available during different periods of the followup were as follows: 1 year, $3.7 \pm 1.3$ (mean, s.D.); 2 years, $2.4 \pm 1.3$; 3 years, $1.2 \pm 0.8 ; 4$ years, $0.8 \pm 0.5$; and 5 years, $1.1 \pm 0.6$. As we found no difference in the TRAb response between young and old patients treated with medication or surgery, the age groups were combined.

Raw data were entered into a SPSS database, and data handling and statistical analyses were performed using SPSS v. 13.0 software (SPSS Inc., Chicago, IL, USA). For comparisons of groups, we used non-parametric tests (Mann-Whitney or Kruskal-Wallis test, depending on the number of strata) and $\chi^{2}$-test (comparison of percentages). The level of significance was set at $5 \%$.

\section{Results}

The levels of TRAb were similar in the three groups of patients before therapy (Fig. 1). During medical therapy and after surgery, the average TRAb in serum gradually decreased to reach the upper level of the normal reference interval for the assay after about 1 year. The TRAb values in these two groups were not significantly different $(P>0.05)$ before therapy and after $6,12,24$, 36,48 , and 60 months.

The therapy with radioiodine induced a different pattern (Fig. 1). A considerable increase in TRAb was observed immediately after therapy with maximal value at the first time point of evaluation (3 months). This peak was followed by a gradual fall, and after about 1 year the average TRAb value had returned to the pretreatment level. Subsequently, TRAb values continued to decrease, but slowly, and average values were well above the normal reference throughout the 5 years

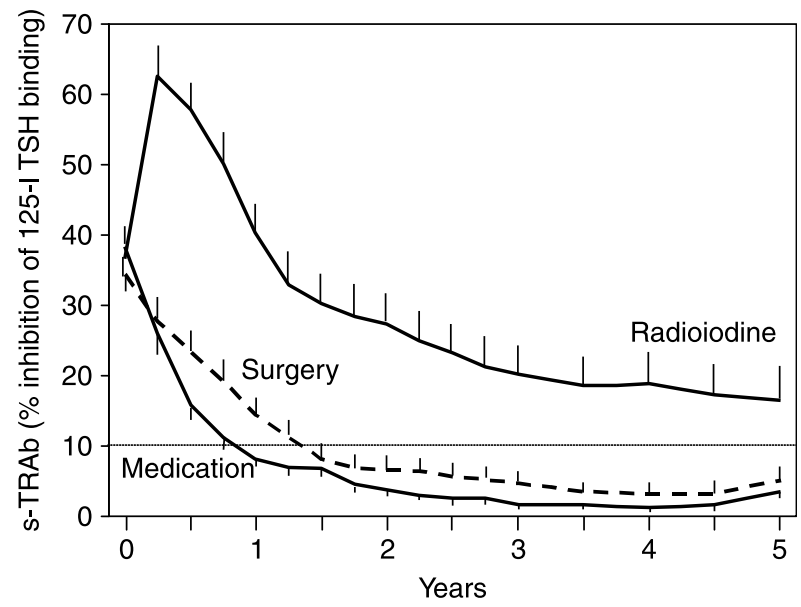

Figure 1 Variations in TSH-receptor antibodies in serum after randomly assigning patients with Graves' hyperthyroidism to radioiodine ( $n=36$; radioiodine was only given to patients being $\geq 35$ years of age), surgery $(n=47)$, or medical therapy $(n=48)$. In all groups, patients were kept euthyroid by the addition of L- $\mathrm{T}_{4}$ to therapy as appropriate. Medical therapy was given for 18 months. The values for the patients who needed a treatment other than the randomized are omitted beyond the time the change occurred. Values are mean \pm S.E.M. The upper normal reference for the TRAb assay was $10 \%$ as indicated by the stapled line. Values before therapy were not different between groups. After therapy, all values were significantly higher for the radioiodine group when compared with values for the medical or surgical therapy groups $(P<0.01)$.

of follow-up. When compared, TRAb values in the three therapy groups were not different before therapy $(P=0.60)$, but significantly different after $6,12,24$, 36,48 , and 60 months $(P<0.003)$.

The frequency of achieving a state where TRAb in serum had become negative $(<10 \%)$ after various time periods is shown in Fig. 2. Corresponding to the variation in the average TRAb values depicted in Fig. 1, the patients became TRAb-negative to a lesser degree and much later after radioiodine therapy than during medical or after surgical therapy.

The favorable outcome with regard to disappearance of TRAb after medical and surgical therapy might have been facilitated by the exclusion of patients with early reoccurrence of hyperthyroidism after surgery $(n=3)$ and patients who did not respond adequately to antithyroid drug therapy $(n=4)$. The available TRAb values from the four patients who were excluded from the medication group are depicted in Fig. 3. All had high levels of TRAb before therapy and no or little decrease in $\mathrm{TRAb}$ values during the period of medication.

Similarly, patients who did not follow the protocol because they had reoccurrence of hyperthyroidism at some point after stopping the medication were excluded from the study from the time they left the protocol. This is illustrated in Fig. 4, showing the average TRAb values in the medication group, and the time of individual reoccurrence of hyperthyroidism. A total of 16 patients experienced reoccurrence of hyperthyroidism after 


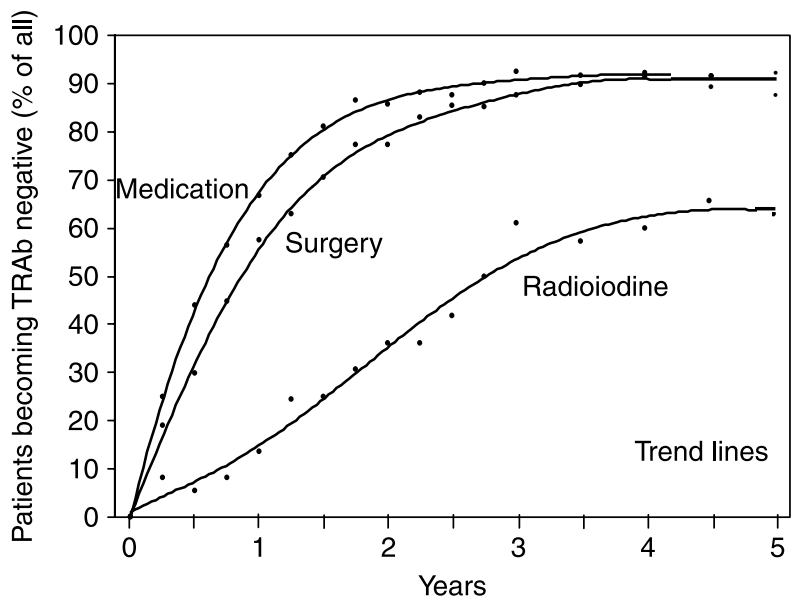

Figure 2 Fractions of patients becoming TRAb-negative (value below $10 \%)$ after radioiodine ( $n=36$; radioiodine was only given to patients $\geq 35$ years of age), surgery $(n=47)$, or medical therapy $(n=48)$. Dots indicate values for the point of time indicated. Lines are trend lines. Medical therapy was given for 18 months. The values for the patients who needed a treatment other than the randomized are omitted beyond the time the change occurred. Values are not different between medication and surgery, but lower after radioiodine $(P<0.01$, at time points $6,12,24,36,48$, and 60 months). See legend to Fig. 1 for further details.

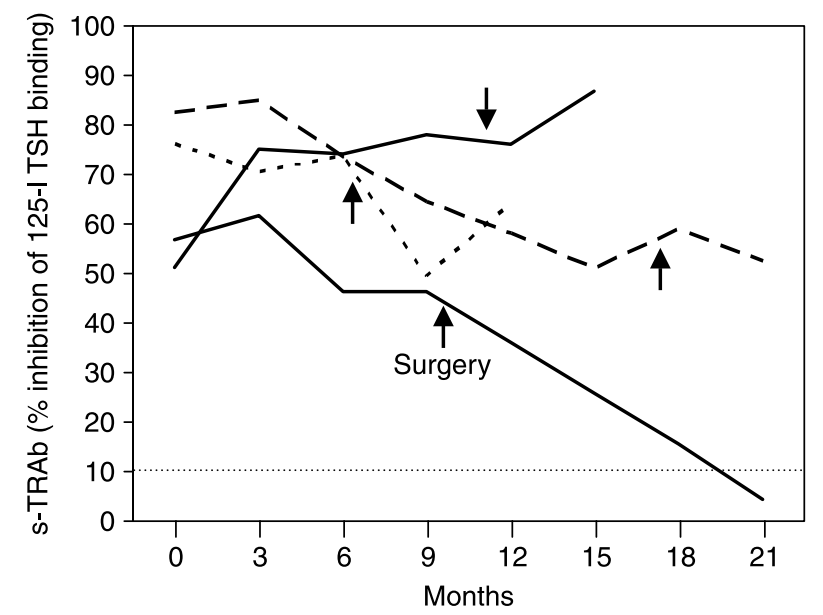

Figure 3 Course of TRAb in serum in four patients who did not respond adequately to medical therapy. They represent $6 \%$ out of the 68 patients initially allocated to medical therapy. The patients did not become euthyroid despite the increase in doses up to $60 \mathrm{mg}$ methimazole or $600 \mathrm{mg}$ propylthiouracil per day. All patients

subsequently underwent subtotal thyroidectomy as indicated by the arrows. The patient who was thyroidectomized after 6 months in addition received radioiodine after 18 months.

medication had been stopped at 18 months. An associated increase in TRAb (measured before or shortly after new therapy) was observed in 14 patients, whereas TRAb was continuously present in one patient with early hyperthyroidism, and not available around the time of new hyperthyroidism in one patient.

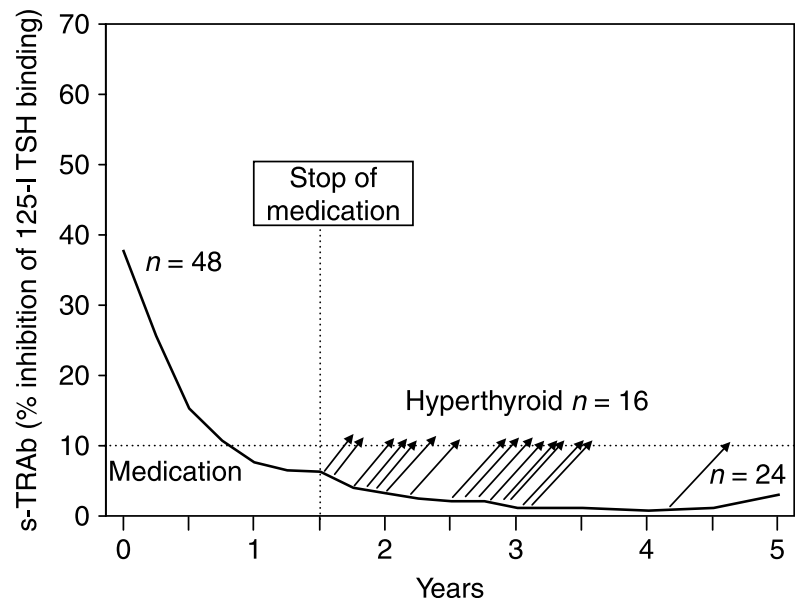

Figure 4 The average TRAb values in the group receiving medical therapy for 18 months $(n=48)$. Arrows indicate the points of time at which 16 patients experienced a reoccurrence of hyperthyroidism. Eight were subsequently treated with radioiodine and the other eight underwent surgery, and they all left the study at the time of new therapy. The individual TRAb values measured in the patients with the reoccurrence of hyperthyroidism were (listed from early to late occurrence of hyperthyroidism), before new hyperthyroidism

$15.2 \%$, at the time of new hyperthyroidism $40.1 \% ; 17.1,30.4 ; 12.2$, $45.0 ;<10.0,11.8 ; 17.4,17.4 ; 14.1$, 23.9; <10.0, 20.3; <10.0, not measured; <10.0, 25.6; <10.0, 57.3; 12.8, 19.9; <10.0, 46.8; $<10.0,15.2 ;<10.0,23.6 ;<10.0,18.8 ;<10.0,24.0$. Another eight patients were lost to follow-up and left: two between 18 and 24 months, three after the 24-month visit, and the remaining after visits at 27,30 , and 33 months.

Individual TRAb values before and at the time of reoccurrence of hyperthyroidism are given in the legend to Fig. 4.

Among the patients who responded to medical therapy, TRAb levels decreased both in those who stayed euthyroid and those experiencing new hyperthyroidism after stopping medication. Average levels were significantly higher at 12 and 18 months of therapy, and more patients were TRAb-positive at 18 months in the group that subsequently developed hyperthyroidism (Fig. 5).

\section{Discussion}

We monitored variations in TRAb in serum for 5 years after the three common types of therapy of patients with hyperthyroidism caused by Graves' disease. A clear difference in the early TRAb response to therapy was observed, with a surge of about one year duration in TRAb after radioiodine therapy. In contrast, TRAb levels decreased in parallel during the first year in patients becoming euthyroid from medication or surgery. After one year, patients continued to enter remission of TSHreceptor autoimmunity with the disappearance of TRAb from serum in all therapy groups, but the frequency of such remission was lower in the radioiodine group. 


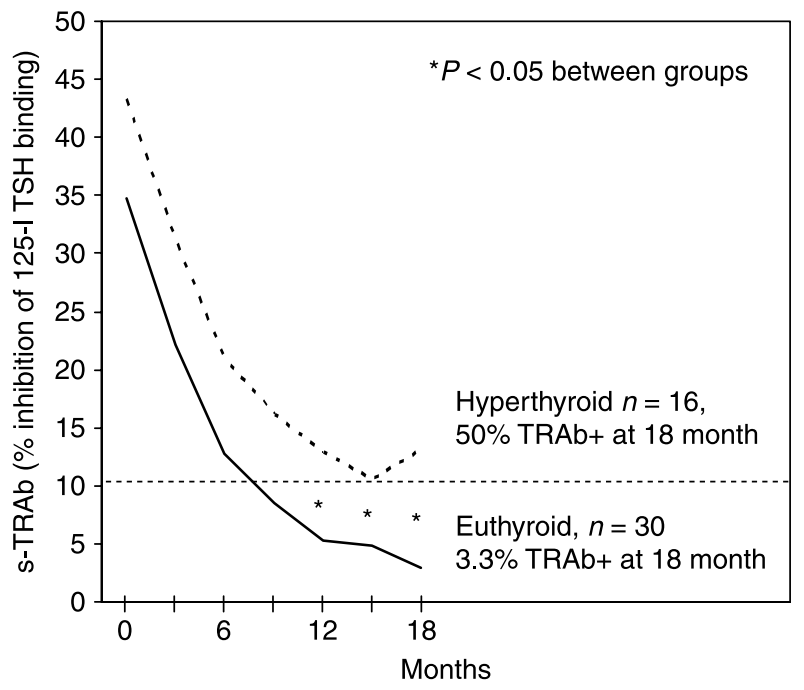

Figure 5 The average TRAb variation in medically treated patients who stayed euthyroid after stop of medical therapy $(n=30)$, and those who became hyperthyroid again $(n=16)$. Two patients who stayed euthyroid but with $<6$ months of follow-up after stop of medication were not included. TRAb values in the two groups of patients were not significantly different during the time period 0-9 months, but thereafter TRAb was significantly higher in the group who developed hyperthyroidism $(P<0.05)$ as indicated by*.

It is well established that radioiodine therapy induces a transient increase in TRAb in serum $(16,17)$, presumably caused by the release of thyroid antigens, but this response has not previously been compared in a randomized study with the response to both surgery and medication. The results indicate that the autoimmune activity in Graves' disease is much higher during the initial period after radioiodine therapy than after other types of therapy, and also that fewer patients treated with radioiodine enter remission of $\mathrm{TSH}$ receptor autoimmunity with the disappearance of TRAb from serum during prolonged observation.

Patients treated with surgery or medication showed a gradual fall in TRAb in serum, and after one year, 50$60 \%$ of the patients had entered remission of TSHreceptor autoimmunity with the disappearance of TRAb from serum. The mechanism behind such a remission during therapy has not been fully clarified. As discussed previously (18), the hyperthyroid state may somehow perpetuate the autoimmune abnormality. When patients become euthyroid after medication or surgery the majority will gradually enter remission of TSHreceptor autoimmunity. However, other possible mechanisms for remission have been proposed (19).

A minority of patients with Graves' disease do not enter remission of TSH-receptor autoimmunity after medication or surgery. In the present study, three patients had reoccurrence of hyperthyroidism after surgery and four patients did not respond properly to medication and subsequently underwent surgery. As shown in Fig. 3, all four patients responding insufficiently to medication had high levels of TRAb with little tendency to enter remission of TSH-receptor autoimmunity during medical therapy. The exclusion of these patients from follow-up made the results after medication and surgery appear more favorable. However, this cannot explain the observed difference in TRAb results after the various therapies. The 5-10\% of patients with the most severe form of Graves' disease may have problems with all types of therapy (20).

Even when patients responded well to medication or surgery, the disappearance of TRAb in serum came gradually over a considerable period of time. It is important to recognize that successful thyroid surgery in Graves' disease will immediately cure the hyperthyroid state, but normalization of the autoimmune abnormality comes much later. Thus, when thyroidectomy is advocated in difficult-to-treat pregnant women with Graves' hyperthyroidism, this may be an effective treatment of the mother, but it may increase the risk of successive fetal hyperthyroidism when compared with the situation under antithyroid drug therapy. TSH-receptor-stimulating antibodies produced in the mother will pass the placenta, and their stimulation of the fetal thyroid will no longer be opposed by antithyroid drugs (21).

The surge in TRAb during the first year after radioiodine therapy is associated with a risk of development or worsening of Graves' orbitopathy (22). In the present study, this risk was nearly entirely confined to patients with the highest levels of serum $\mathrm{T}_{3}$ (11). In Graves' disease, disproportionately high serum $\mathrm{T}_{3}$ is a sign of severe thyroid hyperactivity (23) and the findings further illustrate the problems that may be experienced with patients having the most severe form of Graves' disease.

It has been shown that a period of pretreatment with antithyroid drugs may diminish the TRAb surge after radioiodine $(24,25)$ possibly because the patients have entered partial remission of TSH-receptor autoimmunity (25). Whether this may reduce the risk for worsening of orbitopathy after radioiodine therapy remains to be proven. A study performed in Hong Kong showed no effect of antithyroid drugs given after radioiodine (26), and in another study the majority of patients were TRAb-positive one year after radioiodine, irrespective of pretreatment with methimazole (25). It has been shown that the risk for orbitopathy is much lower if radioiodine is given with a course of prednisolone therapy (27).

A pertinent question remains of whether the persistence in many patients of TRAb, even years after radioiodine therapy, indicates that the chance of longterm improvement of orbitopathy is lower after radioiodine than after other types of therapy. Another consideration is the risk of radioiodine treatment of fetal hyperthyroidism during a later pregnancy in young women (21). Radioiodine is often recommended to young women to overcome any future problems with 
Graves' disease during pregnancy. However, even if the woman is made hypothyroid by radioiodine and subsequently euthyroid by $\mathrm{L}-\mathrm{T}_{4}$ administration, TRAb may remain high for years. Thus, there is a need to measure TRAb in early pregnancy in such women (21) and to follow the fetus carefully for hyperthyroidism, if $\mathrm{TRAb}$ is still present. In the present study, radioiodine was not given to patients below 35 years of age. There is no indication that the TRAb response to radioiodine should be age-dependent, but this possibility should be studied in more detail.

Medical therapy led to a fall in TRAb similar to the fall after surgery. However, this only lasted for the 18-month period the medication was given. After stopping medication, some of the patients had a reactivation of the autoimmune abnormality with an increase in or reappearance of TRAb in serum and with the reoccurrence of hyperthyroidism. The risk of new hyperthyroidism was considerably higher in patients who were TRAbpositive at the end of medical therapy, but the initial TRAb values and the fall in TRAb during therapy overlapped between patients who became hyperthyroid and those who remained euthyroid. In patients who do not accept the risk of new hyperthyroidism after the stop of medication, prolonged medical therapy may be useful (28-31). This should be balanced against the risk of drug side effects (32). More studies are needed on the optimal protocol for medical therapy of Graves' hyperthyroidism, and development of antithyroid drugs with less side effects would make prolonged medical therapy more attractive (20).

If sensitive bioassays are used, all patients with hyperthyroidism caused by Graves' disease have thyroidstimulating antibodies in serum (33). Assays used in clinical routine differ considerably in their ability to detect such antibodies $(4,5)$, but recent generations of assays show high sensitivity and specificity $(14,15)$. In the present study, TRAb was measured using a radioreceptor assay that was able to detect TRAb in $83 \%$ of the untreated patients. All studies using in vitro assays for detecting TRAb in patients with Graves' disease have found a subgroup of patients being TRAb-negative. In general, TRAb-negative patients tend to have a milder disease $(34,35)$. As the aim of the present study was to follow the variations in TRAb after therapy, we excluded patients that were TRAb-negative before therapy.

\section{Conclusion}

We describe in detail the course of TSH-receptor autoimmunity after the three common types of therapy for Graves' hyperthyroidism. Medical therapy and subtotal thyroidectomy were followed by a gradual and parallel remission of TSH-receptor autoimmunity, with the disappearance of TRAb from serum in $70-80 \%$ of the patients after 18 months. After stopping therapy, around $40 \%$ of medically treated patients experienced a reactivation of TSH-receptor autoimmunity and became hyperthyroid again. Radioiodine therapy led to a year-long worsening of autoimmunity against the TSH receptor, and the number of patients entering remission of TSH-receptor autoimmunity with disappearance of TRAb from serum during the following years was considerably lower than with the other types of therapy.

\section{Acknowledgements}

PL: Research Support by BRAHMS Diagnostica, Berlin, Germany.

\section{References}

1 Gerding MN, van der Meer JW, Broenink M, Bakker O, Wiersinga WM \& Prummel MF. Association of thyrotrophin receptor antibodies with the clinical features of Graves' ophthalmopathy. Clinical Endocrinology 200052 267-271.

2 Eckstein AK, Plicht M, Lax H, Hirche H, Quadbeck B, Mann K, Steuhl KP, Esser J \& Morgenthaler NG. Clinical results of antiinflammatory therapy in Graves' ophthalmopathy and association with thyroidal autoantibodies. Clinical Endocrinology 200461 612-618.

3 Fatourechi V. Pretibial myxedema: pathophysiology and treatment options. American Journal of Clinical Dermatology 20056 295-309.

4 Pedersen IB, Knudsen N, Perrild H, Ovesen L \& Laurberg P. TSH-receptor antibody measurement for differentiation of hyperthyroidism into Graves' disease and multinodular toxic goitre: a comparison of two competitive binding assays. Clinical Endocrinology 200155 381-390.

5 Preissner CM, Wolhuter PJ, Sistrunk JW, Homburger HA \& Morris JC, III. Comparison of thyrotropin-receptor antibodies measured by four commercially available methods with a bioassay that uses Fisher rat thyroid cells. Clinical Chemistry $2003 \mathbf{4 9}$ 1402-1404.

6 Davies TF, Ando T, Lin RY, Tomer Y \& Latif R. Thyrotropin receptor-associated diseases: from adenomata to Graves disease. Journal of Clinical Investigation 2005115 1972-1983.

7 Codaccioni JL, Orgiazzi J, Blanc P, Pugeat M, Roulier R \& Carayon P. Lasting remissions in patients treated for Graves' hyperthyroidism with propranolol alone: a pattern of spontaneous evolution of the disease. Journal of Clinical Endocrinology and Metabolism 1988 $67656-662$.

8 Pinchera A, Liberti P, Martino E, Fenzi GF, Grasso L, Rovis L, Baschieri L \& Doria G. Effects of antithyroid therapy on the longacting thyroid stimulator and the antithyroglobulin antibodies. Journal of Clinical Endocrinology and Metabolism 196929 231-238.

9 Aizawa Y, Yoshida K, Kaise N, Kaise K, Fukazawa H, Kiso Y, Mori K, Sayama N, Kikuchi K \& Abe K. Long-term effects of radioiodine on thyrotrophin receptor antibodies in Graves' disease. Clinical Endocrinology $1995 \mathbf{4 2} 517-522$.

10 Takamura Y, Nakano K, Uruno T, Ito Y, Miya A, Kobayashi K, Yokozawa T, Matsuzuka F, Kuma K \& Miyauchi A. Changes in serum TSH receptor antibody (TRAb) values in patients with Graves' disease after total or subtotal thyroidectomy. Endocrine Journal $2003 \mathbf{5 0} 595-601$.

11 Tallstedt L, Lundell G, Torring O, Wallin G, Ljunggren JG, Blomgren $\mathrm{H} \&$ Taube A. Occurrence of ophthalmopathy after treatment for Graves' hyperthyroidism. The Thyroid Study Group. New England Journal of Medicine 199225 1733-1738.

12 Torring O, Tallstedt L, Wallin G, Lundell G, Ljunggren JG, Taube A, Saaf M \& Hamberger B. Graves' hyperthyroidism: treatment with 
antithyroid drugs, surgery, or radioiodine - a prospective, randomized study. Thyroid Study Group. Journal of Clinical Endocrinology and Metabolism 199681 2986-2993.

13 Southgate K, Creagh F, Teece M, Kingswood C \& Rees Smith B. A receptor assay for the measurement of TSH receptor antibodies in unextracted serum. Clinical Endocrinology 198420 539-548.

14 Morgenthaler NG, Nagata A, Katayama S, Bergmann A \& Iitaka M. Detection of low titre TBII in patients with Graves' disease using recombinant human TSH receptor. Clinical Endocrinology 200257 193-198.

15 Smith BR, Bolton J, Young S, Collyer A, Weeden A, Bradbury J, Weightman D, Perros P, Sanders J \& Furmaniak J. A new assay for thyrotropin receptor autoantibodies. Thyroid 200414 830-835.

16 Atkinson S, McGregor AM, Kendall-Taylor P, Peterson MM \& Smith BR. Effect of radioiodine on stimulatory activity of Graves' immunoglobulins. Clinical Endocrinology 198216 537-543.

17 Teng CS, Yeung RT, Khoo RK \& Alagaratnam TT. A prospective study of the changes in thyrotropin binding inhibitory immunoglobulins in Graves' disease treated by subtotal thyroidectomy or radioactive iodine. Journal of Clinical Endocrinology and Metabolism 198050 1005-1010.

18 Laurberg P. Remission of Graves' disease during anti-thyroid drug therapy. Time to reconsider the mechanism? European Journal of Endocrinology 2006155 783-786.

19 McGregor AM, Petersen MM, McLachlan SM, Rooke P, Smith BR \& Hall R. Carbimazole and the autoimmune response in Graves' disease. New England Journal of Medicine 19807 302-307.

20 Laurberg P, Andersen S \& Karmisholt J. Anti-thyroid drug therapy of Graves' hyperthyroidism: realistic goals and focus on evidence. Expert Review of Endocrinology and Metabolism 20061 91-102.

21 Laurberg P, Nygaard B, Glinoer D, Grussendorf M \& Orgiazzi J. Guidelines for TSH-receptor antibody measurements in pregnancy: results of an evidence-based symposium organized by the European Thyroid Association. European Journal of Endocrinology $1998139584-586$.

22 Wiersinga WM \& Bartalena L. Epidemiology and prevention of Graves' ophthalmopathy. Thyroid 200212 855-860.

23 Laurberg P, Vestergaard H, Nielsen S, Christensen SE, Seefeldt T, Helleberg $K$ \& Pedersen KM. Sources of circulating $\mathrm{T}_{3}$ in hyperthyroidism estimated after blocking of type 1 and type 2 iodothyronine deiodinases. Journal of Clinical Endocrinology and Metabolism 200792 2149-2156.

24 Gamstedt A, Wadman B \& Karlsson A. Methimazole, but not betamethasone, prevents ${ }^{131}$ I treatment-induced rises in thyrotropin receptor autoantibodies in hyperthyroid Graves' disease. Journal of Clinical Endocrinology and Metabolism 198662 773-777.

25 Andrade VA, Gross JL \& Maia AL. Serum thyrotropin-receptor autoantibodies levels after ${ }^{131}$ I therapy in Graves' patients: effect of pretreatment with methimazole evaluated by a prospective, randomized study. European Journal of Endocrinology 2004151 467-474.

26 Kung AW, Yau CC \& Cheng A. The incidence of ophthalmopathy after radioiodine therapy for Graves' disease: prognostic factors and the role of methimazole. Journal of Clinical Endocrinology and Metabolism 199479 542-546.

27 Bartalena L, Marcocci C, Bogazzi F, Manetti L, Tanda ML, Dell'Unto E, Bruno-Bossio G, Nardi M, Bartolomei MP, Lepri A, Rossi G, Martino E \& Pinchera A. Relation between therapy for hyperthyroidism and the course of Graves' ophthalmopathy. New England Journal of Medicine $1998 \mathbf{8} 73-78$.

28 Shizume K. Long term antithyroid drug therapy for intractable cases of Graves' disease. Endocrinologia Japonica $1978 \mathbf{2 5}$ 377-379.

29 Slingerland DW \& Burrows BA. Long-term antithyroid treatment in hyperthyroidism. Journal of the American Medical Association $1979302408-2410$.

30 Lippe BM, Landaw EM \& Kaplan SA. Hyperthyroidism in children treated with long term medical therapy: twenty-five percent remission every two years. Journal of Clinical Endocrinology and Metabolism 198764 1241-1245.

31 Azizi F, Ataie L, Hedayati M, Mehrabi Y \& Sheikholeslami F. Effect of long-term continuous methimazole treatment of hyperthyroidism: comparison with radioiodine. European Journal of Endocrinology 2005152 695-701.

32 Cooper DS. Antithyroid drugs. New England Journal of Medicine 20053 905-917.

33 Sato K, Yamazaki K, Yamada E, Kanaji Y, Miura M \& Obara T. Immunoglobulins of untreated Graves' patients with or without thyrotropin receptor antibody (determined by porcine thyrocytes) universally elicit potent thyroid hormone-releasing activity in cultured human thyroid follicles. Thyroid 19999 979-988.

34 Mukuta T, Tamai H, Oshima A, Morita T, Matsubayashi S, Fukata S \& Kuma K. Immunological findings and thyroid function of untreated Graves' disease patients with undetectable TSHbinding inhibitor immunoglobulin. Clinical Endocrinology 199440 215-219.

35 Kawai K, Tamai H, Matsubayashi S, Mukuta T, Morita T, Kubo C \& Kuma K. A study of untreated Graves' patients with undetectable TSH binding inhibitor immunoglobulins and the effect of antithyroid drugs. Clinical Endocrinology 199543 551-556.

Received 21 September 2007

Accepted 8 October 2007 